\title{
EFEITO DA LUZ NO CRESCIMENTO DE MUDAS DE Hymenaea parvifolia Huber. ${ }^{1}$
}

\author{
Breno Marques da Silva e Silva ${ }^{2}$, Juliana Domingues Lima ${ }^{3}$, Vânia Andréa Valente Dantas ${ }^{4}$, Wilson da \\ Silva Moraes ${ }^{5}$ e Débora Zumkeller Sabonaro ${ }^{6}$
}

\begin{abstract}
RESUMO - Este trabalho teve como objetivo determinar o efeito da intensidade de luz no crescimento de mudas de Hymenaea parvifolia Huber., bem como inferir sobre o seu grau de tolerância à sombra. Para tal, foi instalado um experimento em delineamento inteiramente casualizado, com quatro tratamentos (níveis de luz): pleno sol (PS), $50 \%$ de sombreamento, $70 \%$ de sombreamento e sombreamento natural (SN). Os níveis de 50 e $70 \%$ de sombreamento foram obtidos com o uso de telas de polipropileno preto, e o sombreamento natural constituiu a luminosidade natural sob um dossel fechado de floresta. Cada tratamento foi constituído de 10 repetições. Plantas sob sombreamento (50\% e 70\% de sombreamento) apresentaram maior altura, área foliar e razão de área foliar e poucas diferenças no acúmulo de massa seca quando comparadas com plantas mantidas a pleno sol. Como conseqüência, poucas diferenças foram observadas na taxa de crescimento relativo das mudas desses tratamentos. Todavia, mudas mantidas sob sombreamento natural foram as que exibiram menor taxa de crescimento relativo e taxa assimilatória líquida. Em conjunto, os resultados indicaram que Hymenaea parvifolia foi capaz de se ajustar para maximizar a aquisição de luz mesmo em condição muito limitante, como a proporcionada pelo sombreamento natural, e a produção de mudas dessa espécie vegetal pode ser realizada em viveiro desde a pleno sol, como a $50 \%$ ou $70 \%$ de sombreamento.
\end{abstract}

Palavras-chave: Tolerância à sombra, radiação e taxa de crescimento.

\section{EFFECT OF LIGHT INTENSITY ON Hymenaea parvifolia Huber SEEDLING GROWTH}

\begin{abstract}
The objective of this work was to determine the effect of light intensity on the growth of Hymenaea parvifolia Huber seedlings as well as to infer on their degree of shade tolerance. Thus, an experiment was carried out in a completely randomized design, with four treatments (light levels): full sun (FS), 50\% shading, $70 \%$ shading and natural shading (NS). The 50\% and 70\% shading levels were reached with the use of black polypropylene screens and the natural shading consisted of natural luminosity under a closed forest canopy. Each treatment had ten replications. Plants under 50 and $70 \%$ shading presented greater height, leaf area and leaf area ratio and few differences in dry mass accumulation, compared with plants kept under full sun. As a consequence, few differences were observed in the relative growth rate of the seedlings under these treatments. However, seedlings kept under natural shading showed lower relative growth rate and net assimilatory rate. The results as a whole showed that Hymenaea parvifolia was capable of adjusting itself to maximize the acquisition of light under very limiting conditions as that provided for natural shading and that the production of seedlings of this species can be carried out in nurseries under full sun and $50 \%$ or $70 \%$ shading.
\end{abstract}

Keywords: Shade tolerance, radiation and relative growth rate.

\footnotetext{
${ }^{1}$ Recebido em 15.01.2007 e aceito para publicação em 18.06.2007.

${ }^{2}$ Programa de Pós-Graduação em Produção e Tecnologia de Sementes da Universidade Estadual Paulista Júlio de Mesquita Filho, UNESP, Jaboticabal-SP. E-mail: <silvabms@ hotmail.com>.

${ }^{3}$ Campus Experimental de Registro da Universidade Estadual Paulista Júlio de Mesquita Filho, UNESP, RegistroSP. E-mail: <judlima@ registro.unesp.br>.

${ }^{4}$ Curso de Graduação em Ciências Biológicas da Universidade Federal doAmapá, UNIFAP, Macapá-AP.E-mail:<vdantasap@bol.com.br>.

${ }^{5}$ Pólo Regional do Vale do Ribeira, Agência Paulista de Agronegócios, APTA, REgistro-SP. E-mail: <wilson@aptaregional.sp.gov.br>.

${ }^{6}$ Programa de Pós-Graduação em Ciência do Solo da UNESP. E-mail: <dzsabonaro@ hotmail.com>.
} 


\section{INTRODUÇÃO}

Hymenaea parvifolia Huber. é uma espécie florestal nativa da Bacia Amazônica, conhecida popularmente como jutaí-mirim. Apresenta tronco circular de base reta com ritidoma esbranquiçado, fissurado e alburno branco com estrias mais escuras. A lâmina do folíolo é coriácea, brilhante e glabra; a nervura central é destacada na face abaxial, as nervuras secundárias são imersas; e o ápice é agudo (RIBEIRO et al., 1999).

Tem sido apontada como espécie importante para alimentação humana, produção de remédios e alimentação animal, além de sua madeira ser comercializada por populações ribeirinhas da Amazônia (SHANLEY e ROSA, 2004).

A maioria dos projetos que visa à conservação e exploração de espécies nativas florestais depende da formação de mudas. Apesar disso, procedimentos para a produção de mudas são muito escassos, existindo apenas naquelas que detêm maior interesse econômico (CARVALHO, 2000). Assim, o conhecimento do crescimento das plantas no viveiro, em resposta a fatores como água, luz, temperatura, fertilizantes e restrição radicular, é importante para a produção de mudas de qualidade, em quantidade suficiente.

Em relação à luminosidade, estudos sobre o crescimento com árvores nativas têm sido feitos para o conhecimento da resposta de diversas espécies submetidas a diferentes condições de luminosidade. Como resultado, tem sido observado que a eficiência no crescimento da planta pode ser relacionada à habilidade de adaptação de plântulas às condições luminosas do ambiente.

Diante do exposto, este trabalho teve como objetivo determinar o efeito da luz no crescimento de mudas de Hymenaea parvifolia Huber., bem como inferir sobre seu grau de tolerância à sombra.

\section{MATERIAL E MÉTODOS}

Este estudo foi conduzido no viveiro de produção de mudas do Instituto de Pesquisas Científicas e Tecnológicas do Estado do Amapá (IEPA) em 2005, utilizando-se sementes provenientes de frutos coletados em árvores nativas localizadas na Comunidade Quilombola do Rio Curiaú, APA do Curiaú, Macapá, AP.

R. Árvore, Viçosa-MG, v.31, n.6, p.1019-1026, 2007
No laboratório, as sementes foram retiradas dos frutos e escarificadas com lixa de madeira do lado oposto do hilo. Em seguida, foi feita a semeadura direta em sacos plásticos contendo $4 \mathrm{~kg}$ de mistura de solo de floresta e areia (3:1 p/p), suplementada com calcário dolomítico (31\% de $\mathrm{CaO}$ e $18 \%$ de $\mathrm{MgO}$, com PRNT de $90,10 \%, 3 \mathrm{~kg} / \mathrm{m}^{3}$ de solo) e NPK (4-14-8, $2 \mathrm{~kg} / \mathrm{m}^{3}$ de solo). Em seguida, foi instalado um experimento em delineamento inteiramente casualizado, com quatro tratamentos (níveis de luz): pleno sol (PS), 50\% de sombreamento, $70 \%$ de sombreamento e sombreamento natural (SN). Os níveis de 50 e $70 \%$ de sombreamento foram obtidos com o uso de telas de polipropileno preto ("sombrite"), enquanto o sombreamento natural foi obtido sob um dossel fechado de floresta, com redução de cerca de 88 a $92 \%$ da luminosidade natural. Cada tratamento foi constituído de 100 plantas, sendo utilizadas 10 repetições de uma planta em cada um das avaliações, realizadas em intervalos de 30 dias.

Quinze dias após a semeadura, 10 plântulas foram utilizadas para coleta dos dados iniciais de crescimento para avaliação das variáveis altura, número de folhas, área foliar e massa seca do caule, da raiz e das folhas.

Foram avaliadas periodicamente até os 105 dias após a semeadura, as variáveis altura da planta (AP), comprimento do último internódio (CUI), diâmetro do caule (DC), número de folhas (NF), área foliar (AF), massa seca das folhas (MSF), massa seca do caule (MSC) e massa seca da raiz (MSR). A área foliar foi determinada, gravimetricamente, pelo peso do molde das folhas em papel, comparado com a massa de um padrão com área conhecida, e a massa seca da folha determinada após a secagem em estufa a $70^{\circ} \mathrm{C}$ até peso constante.

A partir dos dados primários, variáveis subsequientes foram determinadas: razão parte aérea/raiz (RPAR, massa seca da parte aérea/massa seca da raiz), razão de massa foliar (RMF, massa seca da folha/massa seca total), razão de área foliar (RAF, área foliar/massa seca total) e massa específica da folha (MEF, massa seca da folha/ área foliar). Também, foram calculadas a taxa média de crescimento absoluto $\left(\mathrm{TCA}=\left(\mathrm{MS}_{2}-\mathrm{MS}_{1}\right) /\left(\mathrm{t}_{2}-\mathrm{t}_{1}\right)\right.$, a taxa média de crescimento relativo da massa seca $\left(\mathrm{TCR}_{\mathrm{MS}}\right.$, $\left.=\left(\operatorname{lnMS} S_{2}-\operatorname{lnMS} S_{1}\right) /\left(\mathrm{t}_{2}-\mathrm{t}_{1}\right)\right)$, a taxa média de crescimento relativo da área foliar média $\left(\mathrm{TCR}_{\mathrm{AF}},=\left(\ln \mathrm{AF}_{2}-\ln \mathrm{AF}_{1}\right) /\right.$ $\left.\left(\mathrm{t}_{2}-\mathrm{t}_{1}\right)\right)$ e a taxa média assimilatória líquida $\left(\mathrm{TAL}=\left[\left(\mathrm{MS}_{2}-\right.\right.\right.$ 
$\left.\left.\left.\mathrm{MS}_{1}\right) /\left(\mathrm{t}_{2}-\mathrm{t}_{1}\right)\right] /\left[\left(\ln \mathrm{AF}_{2}-\ln \mathrm{AF}_{1}\right) /\left(\mathrm{AF}_{2}-\mathrm{AF}_{1}\right)\right]\right)$, em que MS $=$ massa seca, $\mathrm{AF}=$ área foliar e $\mathrm{t}=$ tempo, com índice ${ }_{1}$ $=$ valor inicial e índice ${ }_{2}=$ valor final (HUNT, 1982).

Os dados foram submetidos à análise de variância pelo teste $\mathrm{F}$, sendo as médias dos tratamentos aos 105 dias após a semeadura, comparadas pelo teste de Tukey a $5 \%$ de probabilidade. Foi realizada também a análise de regressão polinomial para estudar o incremento da área foliar e o acúmulo de massa seca total, em função do número de dias após a semeadura nas mudas dos diferentes tratamentos.

\section{RESULTADOS E DISCUSSÃO}

Neste estudo, a área foliar (AF) das mudas aos 105 dias após a semeadura foi superior em plantas mantidas sob $70 \%$ de sombreamento, quando comparadas com os demais tratamentos. Entre os tratamentos a pleno sol e $50 \%$ de sombreamento, houve pouca diferença na área foliar (Figura 1A). O aumento da área foliar é um dos mecanismos utilizados pela planta para aumentar a superfície fotossintética, assegurando-se um rendimento fotossintético mais eficiente em baixa intensidade luminosa e, conseqüentemente, compensando a baixa taxa fotossintética por unidade de área de folha, uma característica das folhas sombreadas (JONES e McLEOD, 1990). Em outras espécies, também foi observado maior incremento de área foliar em mudas mantidas sob sombreamento, como Croton urucurana (ALVARENGA et al., 2003) e Eugenia uniflora (SCALON et al., 2001).

O acúmulo de massa seca total (MST) foi semelhante nos tratamentos a pleno sol, 50 e $70 \%$ de sombreamento. Isso demonstra que as diferenças apresentadas no incremento da área foliar nesses níveis de sombreamento foram suficientes para manter o ganho de biomassa (Figura 1B).

Plantas mantidas a $70 \%$ de sombreamento foram as que apresentaram maior altura (AP), seguidas de plantas mantidas sob $50 \%$ de sombreamento, pleno sol e, por último, de plantas mantidas sob sombreamento natural (Tabela 1). O comprimento do último internódio (CUI) foi superior em plantas submetidas a algum tipo de sombreamento quando comparadas com plantas mantidas a pleno sol.

Para o diâmetro do colo (DC) e o número de folhas (NF), plantas sob sombreamento natural apresentaram os menores valores médios, não havendo diferenças entre plantas a pleno sol e 50 e $70 \%$ de sombreamento (Tabela 1 ).
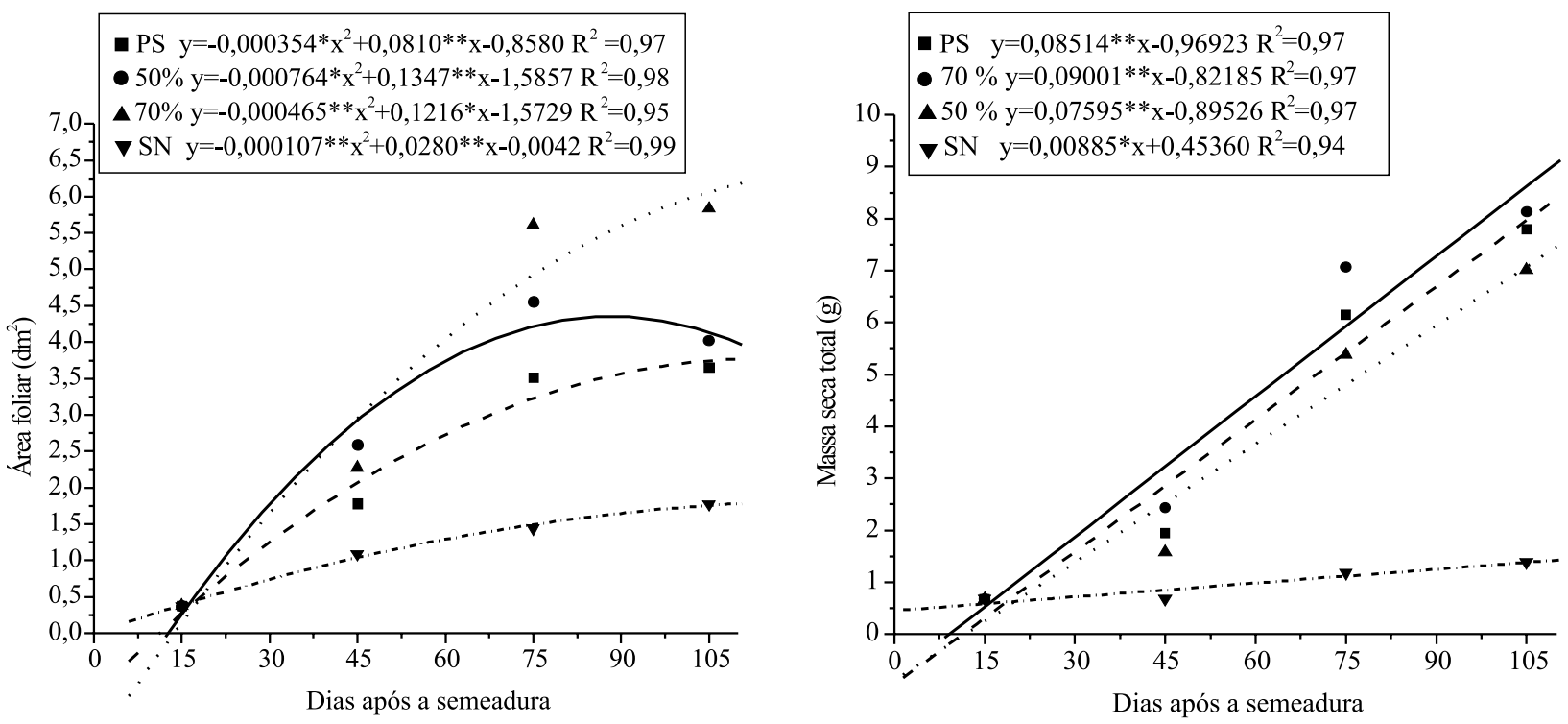

Figura 1 - Área foliar (AF) (A) e massa seca total (MST) (B) após a semeadura de mudas de Hymenaea parvifolia cultivadas sob sombreamento natural (SN), 70\% e 50\% de sombreamento e pleno sol (PS). * e ** significativos a 5\% e $1 \%$ de probabilidade, respectivamente, pelo teste $\mathrm{F}$.

Figure 1 - Leaf area (LA) (A) and total dry mass (TDM) (B) after sowing of Hymenaea parvifolia seedlings grown under natural shading (NS), $70 \%$ and $50 \%$ shading and full sun (FS). * and **: significant at $5 \%$ and $1 \%$ probability, respectively, by the F test. 
Tabela 1 - Médias da altura da planta (AP), comprimento do último internódio (CUI), diâmetro do colo (DC), número de folhas (NF), razão parte aérea/raiz (RPAR), razão de área foliar (RAF), massa específica da folha (MEF) e razão de massa foliar (RMF) de mudas de Hymenaea parvifolia cultivadas sob pleno sol (PS), 50\% de sombreamento, $70 \%$ de sombreamento e sombreamento natural (SN). Medidas feitas aos 105 dias após a semeadura

Table 1 - Means of plant height (PH), last internode length (LIL), stem diameter (SD), leaf number (LN), shoot/root ratio $(S R R)$, leaf area ratio (LAR), specific leaf mass (SLM), leaf mass ratio (LMR) of Hymenaea parvifolia seedlings grown under full sun (FS), 50\% shading, 70\% shading and natural shading (NS). Measurements performed 105 days after sowing

\begin{tabular}{lcccccccc}
\hline & AP $(\mathrm{cm})$ & CUI $(\mathrm{cm})$ & DC $(\mathrm{cm})$ & NF & RPAR & $\operatorname{RAF}_{\left(\mathrm{dm}^{2} \mathrm{~g}^{-1}\right)} \mathrm{MEF}\left(\mathrm{g} \mathrm{dm}^{-2}\right)$ & $\left.\left.\mathrm{RMF}_{(\mathrm{g} \mathrm{g}}\right)^{-1}\right)$ \\
\hline PS & $42,56 \mathrm{c}$ & $2,16 \mathrm{~b}$ & $2,10 \mathrm{a}$ & $8,80 \mathrm{a}$ & $2,14 \mathrm{c}$ & $0,47 \mathrm{c}$ & $0,73 \mathrm{a}$ & $0,41 \mathrm{~b}$ \\
$50 \%$ & $50,06 \mathrm{~b}$ & $3,16 \mathrm{ab}$ & $2,40 \mathrm{a}$ & $8,80 \mathrm{a}$ & $2,05 \mathrm{c}$ & $0,50 \mathrm{c}$ & $0,64 \mathrm{ab}$ & $0,40 \mathrm{~b}$ \\
$70 \%$ & $59,86 \mathrm{a}$ & $4,36 \mathrm{a}$ & $2,00 \mathrm{a}$ & $10,00 \mathrm{a}$ & $3,82 \mathrm{~b}$ & $0,83 \mathrm{~b}$ & $0,54 \mathrm{bc}$ \\
SN & $28,28 \mathrm{~d}$ & $4,96 \mathrm{a}$ & $1,20 \mathrm{~b}$ & $5,00 \mathrm{~b}$ & $6,25 \mathrm{a}$ & $1,29 \mathrm{a}$ & $0,45 \mathrm{ab}$ \\
\hline
\end{tabular}

Médias seguidas da mesma letra em cada avaliação não diferem entre si, a 5\% de probabilidade, pelo teste Tukey.

Means followed by the same letter in the column do not differ among them, at $5 \%$ probability by the Tukey test.

O maior crescimento em altura das plantas com redução no nível de luminosidade foi observado em outras espécies florestais sob sombreamento, como Amburana cearensis, Tabebuia avellanedae, Erythrina speciosa (ENGEL e POGGIANI, 1990), Bombacopsis glabra (SCALON et al., 2003), Croton urucurana (ALVARENGA et al., 2003), Maclura tinctoria e Senna macranthera (ALMEIDA et al., 2005). Todavia, isso não ocorreu em Hymenaea courbaril e Acacia mangium (ALMEIDA et al., 2005) e Cedrela fissilis (SANTOS et al., 2006), quando comparado com plantas mantidas a pleno sol.

Com relação ao diâmetro do colo, as respostas ao sombreamento apresentadas por outras espécies são variadas. Maclura tinctoria e Hymenaea courbaril também não apresentaram diferenças nessa variável a 30 e $50 \%$ de sombreamento em relação a mudas cultivadas a pelo sol (ALMEIDA et al., 2005). Todavia, em Acacia mangium houve redução no diâmetro do colo com o sombreamento (ALMEIDA et al., 2005).

O aumento no comprimento do último internódio expressa, de maneira mais aproximada, a sensibilidade da planta à redução na disponibilidade de radiação, observada em todas as intensidades de sombreamento em relação às plantas cultivadas em pleno sol (Tabela 1). Segundo Smith e Whitelam (1990), essa resposta é esperada em plantas sob condição de sombreamento natural por ser uma resposta morfogênica típica.

A razão da área foliar (RAF) que expressa a área útil da planta para fotossíntese (BENINCASA, 2003), ou seja, quanto em área é necessário para se produzir $1 \mathrm{~g}$ de matéria seca, foi mais alta em plântulas cultivadas sob sombreamento natural, seguida por plântulas cultivadas sob $70 \%$ de sombreamento e, por último, de plântulas cultivadas sob $50 \%$ de sombreamento e pleno sol, que não diferiram entre si (Tabela 1). Isso indica que a dimensão relativa do aparelho assimilador variou em função dos níveis de sombreamento. A massa específica da folha (MEF) que reflete a espessura da folha tendeu a diminuir com o aumento do sombreamento (Tabela 1), o que demonstra mudança anatômica no tecido foliar. Langenheim et al. (1984), estudando a resposta fotossintética de plântulas de Hymenaea parvifolia crescendo sob sombra (6\% de luz) e sob radiação plena ( $100 \%$ de luz), já haviam observado menor massa específica da folha e número de folhas em plantas crescendo sob sombra.

A razão de massa da foliar (RMF), que expressa a fração de matéria seca não exportada da folha (BENINCASA, 2003), foi mais alta no tratamento sombreamento natural, seguido de $70 \%$ de sombreamento (Tabela 1), indicando menor exportação de biomassa para outras partes da planta com a redução da luminosidade.

Quanto à partição da biomassa, poucas diferenças podem ser observadas no acúmulo de matéria seca da folha (MSF) e matéria seca do caule (MSC) entre plantas dos tratamentos a pleno sol, 50 e $70 \%$ ao longo do período de avaliação (Figura 2). No entanto, no tratamento pleno sol já se observou menor acúmulo de matéria seca nos referidos órgãos aos 45 dias após a semeadura (DAS).

Sob sombreamento mais intenso $(70 \%$ de sombreamento e sombreamento natural) ocorreu redução na massa seca acumulada na raiz (MSR), em relação a níveis mais altos de luz (pleno sol e $50 \%$ de 
sombreamento) (Figuras 2 e 3). Essa tendência, segundo Carvalho et al. (2006), permite maior absorção de água e nutrientes, estratégia que garantiria à planta capacidade de suportar taxas mais elevadas de fotossíntese e transpiração em ambientes mais iluminados. Neste estudo, essa tendência pode ser também confirmada pelos valores mais baixos de razão parte aérea/raiz (RPAR) observada em plântulas cultivadas em níveis mais altos de luz (Tabela 1). Numa outra visão, plantas cultivadas em baixa disponibilidade de luz tendem a investir mais biomassa na parte aérea em detrimento da raiz (LEE et al., 1996), fato ocorrido com maior intensidade em plantas mantidas sob $70 \%$ de sombreamento e sombreamento natural (Figura 3).

Não houve diferenças na taxa de crescimento absoluto (TCA), que reflete a velocidade de crescimento (BENINCASA, 2003), em plantas mantidas a pleno sol (PS) e 50\% de sombreamento, havendo redução nessa variável com o aumento do sombreamento (Tabela 2).

A taxa de assimilação líquida (TAL) é um reflexo da capacidade fotossintética da planta em relação à área fotossintetizante (HUNT, 1982), e a taxa de crescimento relativo (TCR) é função da taxa assimilação líquida (TAL) e da razão de área foliar (RAF), e essas duas últimas variáveis tendem a variar inversamente com a variação da irradiância (OSUNKOYA et al., 1994).

As plantas mantidas a pleno sol, 50 e $70 \%$ de sombreamento apresentaram taxa de crescimento relativo da massa seca $\left(\mathrm{TCR}_{\mathrm{MS}}\right)$ e taxa de crescimento relativo da área foliar ( $\mathrm{TCR}_{\mathrm{AF}}$ ) semelhantes, não diferindo entre $\mathrm{si}$, mas apenas das plantas mantidas sob sombreamento natural (Tabela 2). Apesar de $\mathrm{TCR}_{\mathrm{MS}}$ e $\mathrm{TCR}_{\mathrm{AF}}$ não diferirem entre os tratamentos a pleno sol, 50 e $70 \%$ de sombreamento, a TAL obtida para o tratamento $70 \%$ de sombreamento se mostrou reduzida em relação a pleno sol e $50 \%$ de sombreamento. Isso demonstra que a $70 \%$ de sombreamento já existia limitação significativa na assimilação líquida de carbono por unidade de área foliar devido ao déficit de luz. Uma vez que não houve alterações nas taxas de crescimento entre esses três tratamentos, provavelmente no tratamento $70 \%$ de sombreamento a maior razão de área foliar (RAF) (Tabela 1) obtida pelo aumento de área foliar compensou o déficit de luz, não afetando significativamente o crescimento da plântula. Ainda sob sombreamento natural, as mudas apresentaram taxa assimilatória líquida (TAL) e taxa de crescimento relativo $\left(\mathrm{TCR}_{\mathrm{MS}}\right)$ positivas (Tabela 2). Isso indica que a taxa fotossintética foi superior à taxa respiratória no período avaliado, gerando um balanço positivo de carbono capaz de sustentar o crescimento sob limitação acentuada de luminosidade, o que permitiria o estabelecimento e sobrevivência em condições naturais.
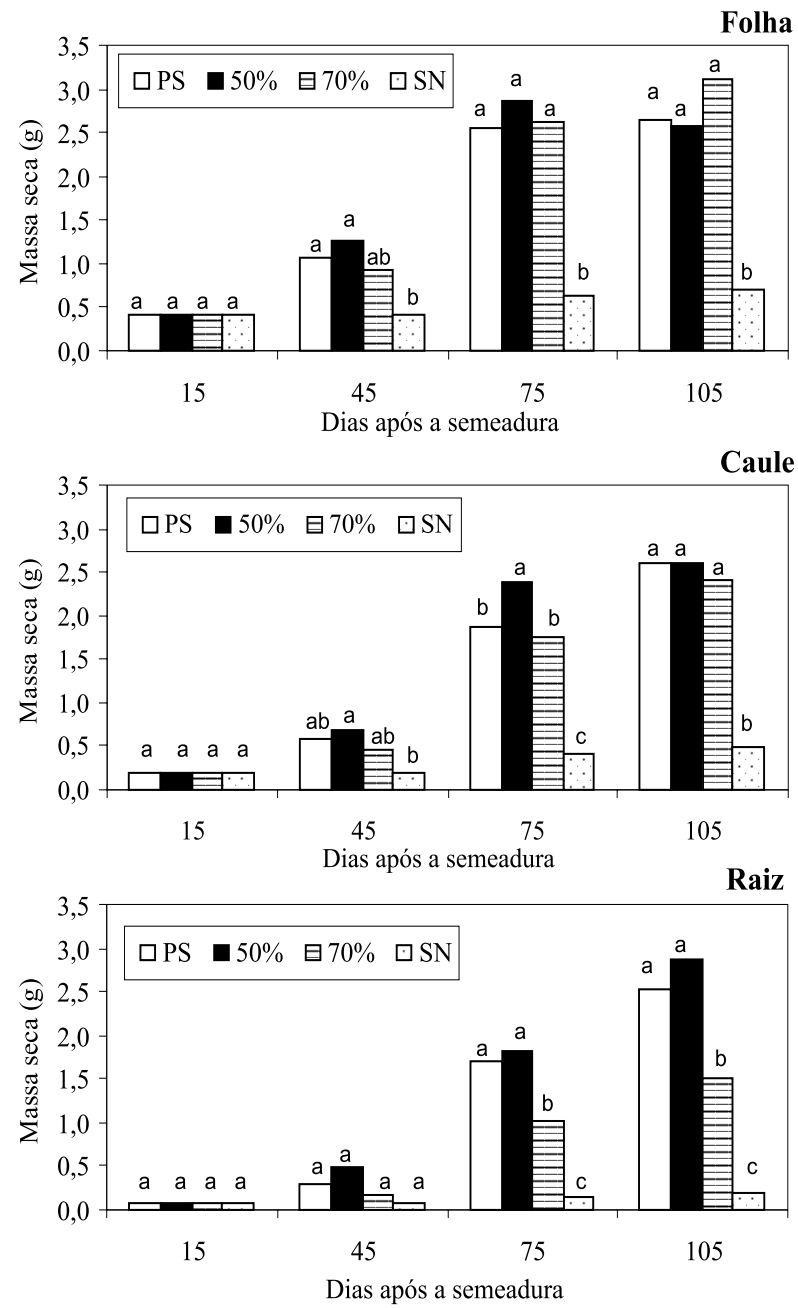

Figura 2 - Massa seca das folhas (MSL) (A), do caule (MSC) (B) e da raiz (MSR) (C) após a semeadura de mudas de Hymenaea parvifolia cultivadas sob sombreamento natural (SN), 70\% de sombreamento, $50 \%$ de sombreamento e pleno sol (PS). Médias seguidas da mesma letra em cada avaliação não diferem entre si, a $5 \%$ de probabilidade, pelo teste Tukey.

Figure 2-Leaf dry mass (LDM) (A), stem dry mass (SDM) (B) and root dry mass (RDM) (C), after sowing of Hymenaea parvifolia seedlings grown under natural shading (NS), $70 \%$ and $50 \%$ shading and full sun (FS). Means followed by the same letter in each evaluation do not differ among them, at $5 \%$ of probability by the Tukey test.

R. Árvore, Viçosa-MG, v.31, n.6, p.1019-1026, 2007 

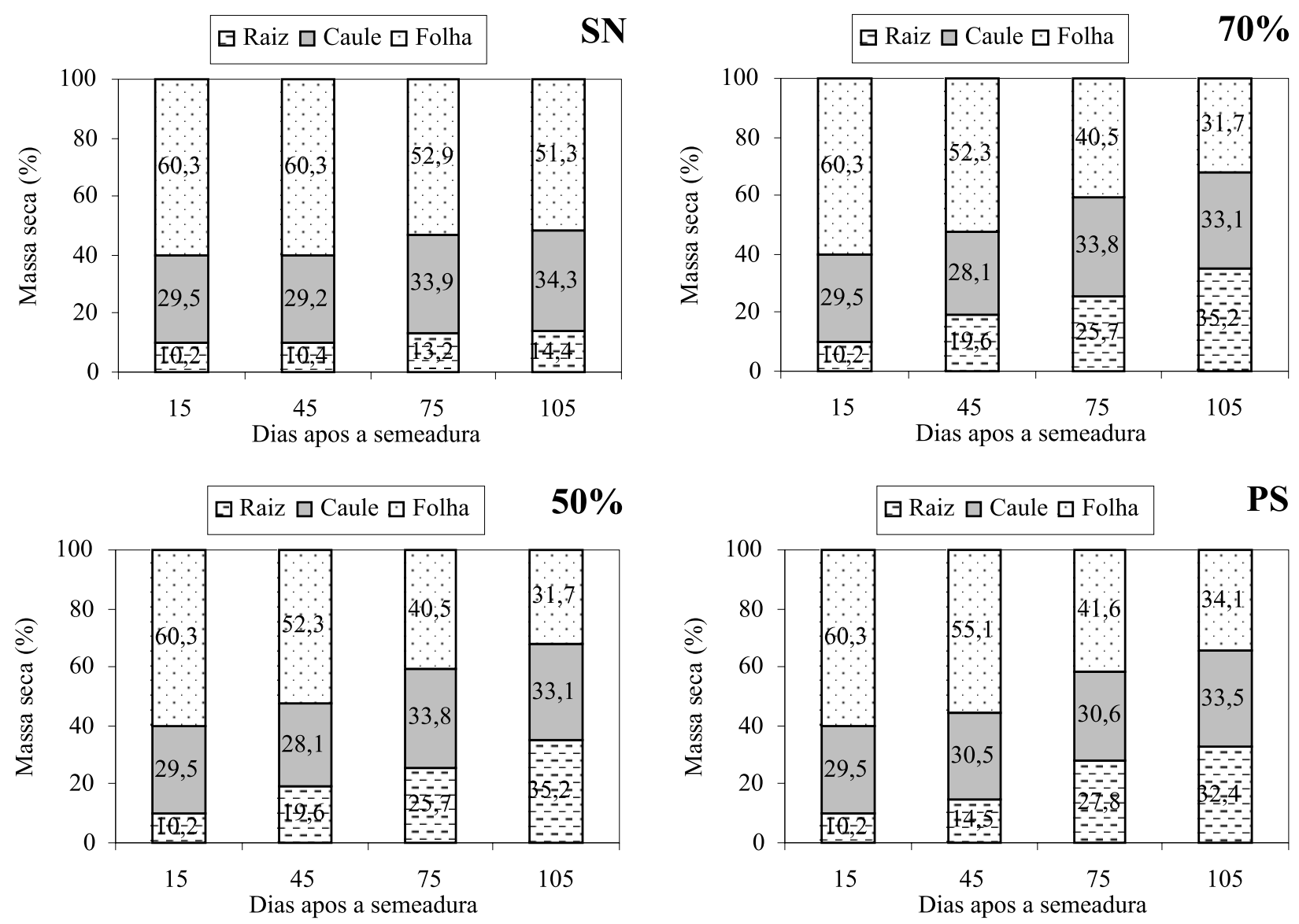

Figura 3 - Média da fração de partição de biomassa em folha, caule e raiz, após a semeadura de mudas de Hymenaea parvifolia cultivadas sob: A - sombreamento natural (SN), B - 70\% de sombreamento, C - 50\% de sombreamento e D - pleno sol (PS).

Figure 3 - Leaf, stem and root biomass allocation fraction mean after sowing of Hymenaea parvifolia seedlings grown under: $\boldsymbol{A}$ - natural shading (NS), $\boldsymbol{B}-70 \%$ shading, $\boldsymbol{C}-50 \%$ shading and $\boldsymbol{D}$ - full sun (FS).

A possibilidade de usar o sombreamento natural na produção de mudas surgiu do fato de alguns agricultores não possuírem viveiro com tela de sombreamento, além de a análise de crescimento de mudas submetidas a essa condição poder dar uma idéia do grau de tolerância à sombra apresentado pela espécie.

A maioria dos estudos com sombreamento tem dado ênfase apenas para a redução na quantidade de luz fornecida e não nas alterações da composição espectral da luz. Segundo Andrade et al. 2004, o uso de telas de polipropileno (sombreamento artificial) na análise da resposta de plantas ao sombreamento apresenta a vantagem de isolar o efeito da intensidade da radiação fotossinteticamente ativa de outras interferências que ocorrem no sombreamento natural por árvores, como a competição por água e nutrientes. Entretanto, essa técnica possui alguns inconvenientes. Um deles é que o sombreamento natural proporcionado por árvores altera também a qualidade (razão vermelho:vermelho distante) da luz incidente no dossel (WILSON e LUDLOW, 1991), ao passo que as telas de polipropileno, embora eficientes na redução da intensidade da luz, não alteram sua qualidade (HUBER e STUEFER, 1997). Portanto, a baixa "performance" no crescimento apresentada pelas mudas submetidas ao sombreamento natural também pode ser atribuída à redução da relação vermelho:vermelho distante, que possui importantes efeitos sobre a morfogênese das plantas (SMITH e WHITELAM, 1990). 
Souza e Válio (2003) compararam o crescimento de plântulas de diversas espécies arbóreas tropicais sob radiação plena, sombreamento natural e sombreamento artificial. Observaram que o sombreamento natural teve efeito mais severo na redução da área foliar e na taxa de crescimento relativo que o sombreamento artificial, como observado neste estudo.

Baseado nos resultados, pode-se sugerir que Hymenaea parvifolia é tolerante ao sombreamento. Em estudos com outra espécie do mesmo gênero, $H$. courbaril foi considerada espécie tolerante à sombra (SOUZA e VÁLIO, 2003; ALMEIDA et al., 2005). Assim supõe-se, então, que em condições naturais Hymenaea parvifolia apresentaria melhores chances de regeneração sob a cobertura da floresta, tolerando, inclusive, intensidades luminosas bastante reduzidas sob dossel fechado.

\section{CONCLUSÕES}

Nas condições em que este estudo foi realizado, Hymenaea parvifolia foi capaz de se ajustar, de maneira eficaz, seu comportamento fisiológico, para maximizar a aquisição de luz. Assim, recomenda-se a produção de mudas desta espécie desde a pleno sol como a 50 ou $70 \%$ de sombreamento, optando pelo uso do sombreamento em regiões onde o déficit de pressão de vapor for alto ou a irrigação for precária.

\section{REFERÊNCIAS}

ANDRADE, C. M. S. et al. Crescimento de gramíneas e leguminosas forrageiras tropicais sob sombreamento. Pesquisa Agropecuária Brasileira, v.39, n.3, p.263-270, 2004.

ALMEIDA, S. M. Z. et al. Alterações morfológicas e alocação de biomassa em plantas jovens de espécies florestais sob diferentes condições de sombreamento Ciência Rural, v.35, n.1, p.62-68, 2005.

ALVARENGA, A. A. et al. Effects of different light levels on the initial growth and photosynthesis of Croton urucurana Baill. in southeastern Brazil.

Revista Árvore, v.27, n.1, p.53-57, 2003.

BENINCASA, M. M. P. Análise de crescimento de plantas: noções básicas. 2.ed. Jaboticabal: FUNEP, 2003. 41p.
CARVALHO, P. E. R. Produção de mudas de espécies nativas por sementes e a implantação de povoamentos. In: GALVÃO, A. P. M. (Org.). Reflorestamento de propriedades rurais para fins produtivos e ambientais: um guia para ações municipais e regionais. Brasília: Embrapa, 2000. p.151-174.

CARVALHO, N. O. S. et al. Initial growth of licuri plants (Syagrus coronata (Mart.) Becc.) under different light intensity. Revista Árvore, v.30, n.3, p.351-357, 2006.

ENGEL, V. L.; POGGIANI, F. Influência do sombreamento sobre o crescimento de mudas de algumas essências nativas e suas implicações ecológicas e silviculturais. IPEF, n.43/44, p. 1-10, 1990.

HUBER, H.; STUEFER, J. F. Shade-induced changes in the branching pattern of a stoloniferous herb: functional response or allometric effect? Oecologia, v.110, n.4, p.478-486, 1997.

HUNT, R. Plant growth curves. The functional approach to plant growth analysis. London: Edward Arnold, 1982. 247p.

JONES, R. H.; McLEOD, K. W. Growth and photosynthetic responses to a range of light environments in Chinese tollow tree and Carolina ash seedlings. Forest Science, v.36, n.4, p.851-862, 1990.

LANGENHEIM, J. H. et al. Photosynthetic responses to light in seedlings of select Amazonian and Australian rainforest tree species. Oecologia, v.63, n.2, p.215-224, 1984.

LEE, D. W. et al. Irradiance and spectral quality affect Asian tropical rain forest tree seedling development. Ecology, v.77, n.2, n.568-580, 1996.

OSUNKOYA, O. O. et al. Influence of seed size and seedling ecological attributes on shade-tolerance of rain forest tree species northern Queesland. Journal of Ecology, v.82, p.149-163, 1994.

R. Árvore, Viçosa-MG, v.31, n.6, p.1019-1026, 2007 
PEZZUTTI, R. V.; SCNUMACHER, M. V.; HOPPE, J. M. Crescimento de mudas de Eucalyptus globulus em resposta a fertilização. Ciência Florestal, v.9, n.2, p.117-125, 1999.

RIBEIRO, J. E. L. S. et al. Flora da Reserva Ducke. Manaus: Instituto Nacional de Pesquisas da Amazônia (INPA) e Department for International Development (DFID), 1999. 800p.

SANTOS, D. L. et al. Morphological and physiological responses of Cedrela fissilis Vellozo (Meliaceae) seedlings to light.

Brazilian Archives of Biology and Technology, v.49, n.1, p.171-182, 2006.

SCALON, S. P. Q.; ALVARENGA, A. A. Efeito do sombreamento sobre a formação de mudas de pau-pereira (Playcyamus regnellii Benth.).

Revista Árvore, v.17, n.3, p.265-270, 1993.

SCALON, S. P. Q. et al. Germinação e crescimento de mudas de pitangueira (Eugenia uniflora L.) sob condições de sombreamento. Revista Brasileira de Fruticultura, v.23, n.3, p.652-655, 2001.

R. Árvore, Viçosa-MG, v.31, n.6, p.1019-1026, 2007
SCALON, S. P. Q. et al. Initial growth of Bombacopsis glabra (Pasq.) A. Robyns seedlings under shading conditions. Revista Árvore, v.27, n.6, p.753-758, 2003.

SHANLEY, P.; ROSA, N. A. Cover article: Eroding knowledge: An Ethnobotanical Inventory in Eastern Amazonia's Logging Frontier.

Economic Botany, v.58, n.2, p.135-160, 2004.

SMITH, H.; WHITELAM, G. C. Phytochrome, a family of photoreceptors whith multiple physiological roles. Plant Cell and Environment, v.13, p.695-707, 1990.

SOUZA, R. P.; VÁLIO, I. F. M. Seedling growth of fifteen Brazilian tropical tree species differing in successional status. Revista Brasileira de Botânica, v.26, n.1, p.35-47, 2003.

WILSON, J. R.; LUDLOW, M. M. The environment and potential growth of herbage under plantations. In: SHELTON, H. M.; STÜR, W. W. (Eds.).

Forages for plantation crops. Canberra: Australian Centre for International Agricultural Research, 1991. p.10-24. (ACIAR Proceedings, 32). 